\title{
High-intensity focused ultrasound of uterine fibroids and adenomyosis: maneuver technique for bowel loops located inside the treatment window
}

Appearance of bowel loops in the sonication beam path during high-intensity focused ultrasound (HIFU) ablation therapy is a problematic condition. Filling bladder, filling rectum and, emptying bladder (BRB) maneuver technique might be helpful in producing a non-bowel treatment window for HIFU ablation of uterine fibroids and adenomyosis and ensuring the safety profile for patients.

\section{KEYWORDS: high-intensity focused ultrasound - uterine fibroids - adenomyosis - BRB maneuver technique}

\section{Introduction}

Uterine fibroids and adenomyosis are two commonly gynecological benign tumors negatively affected women's health [1,2]. High-intensity focused ultrasound (HIFU) is a promisingly alternative treatment to conventional surgery and is increasingly worldwide used because of its completely non-invasive method [3-6]. During the ablation procedure, appearance of bowel loops inside the treatment window was generally problematic because hard elements and air bubbles inside bowel loops absorb and reflect ultrasound energy caused unpredictable thermal injury even bowel perforation $[7,8]$. Thus, in this concise communication, we aimed to introduce the filling bladder, filling rectum, and emptying bladder (BRB) technique for manipulating bowel loops out of the treatment window in order to establish the safety profile for patients.

\section{BRB technique}

Filling the bladder with normal saline via a Foley catheter will not only elevate the uterus upward but also shove the bowel loops out of the treatment window when they tend to move into the space between the abdominal wall and the uterus as seen in Figure $1[9,10]$.

Filling the rectum with ultrasound gel through a rectal catheter is also beneficial for pressing the uterus forward and reducing the distance between the uterus and anterior abdominal wall as seen in Figure 2. In addition, this manipulation also reduces bowel loop movements into the space between the uterus and the rectum $[9,10]$.

Finally, emptying bladder concurrent with

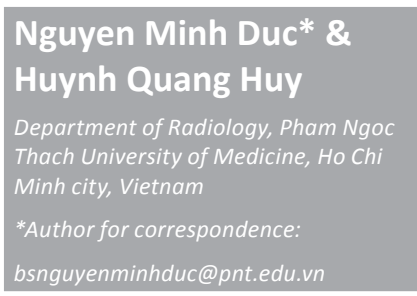

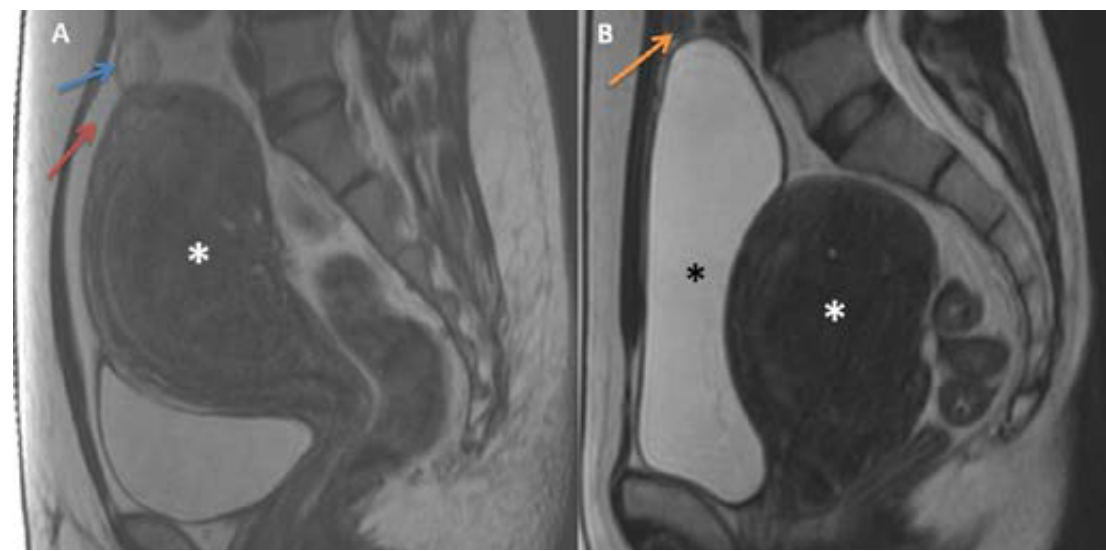

Figure 1. (A) Sagittal T2W images show adenomyosis on the posterior wall of the anteverted uterus (white asterisk) with bowel loops above the tumor (blue arrow), which tend to move into the space between the tumor and abdominal wall (red arrow). (B) Filling bladder with $400 \mathrm{ml}$ normal saline (black asterisk) generates bowel loops out of the treatment window (orange arrow). 

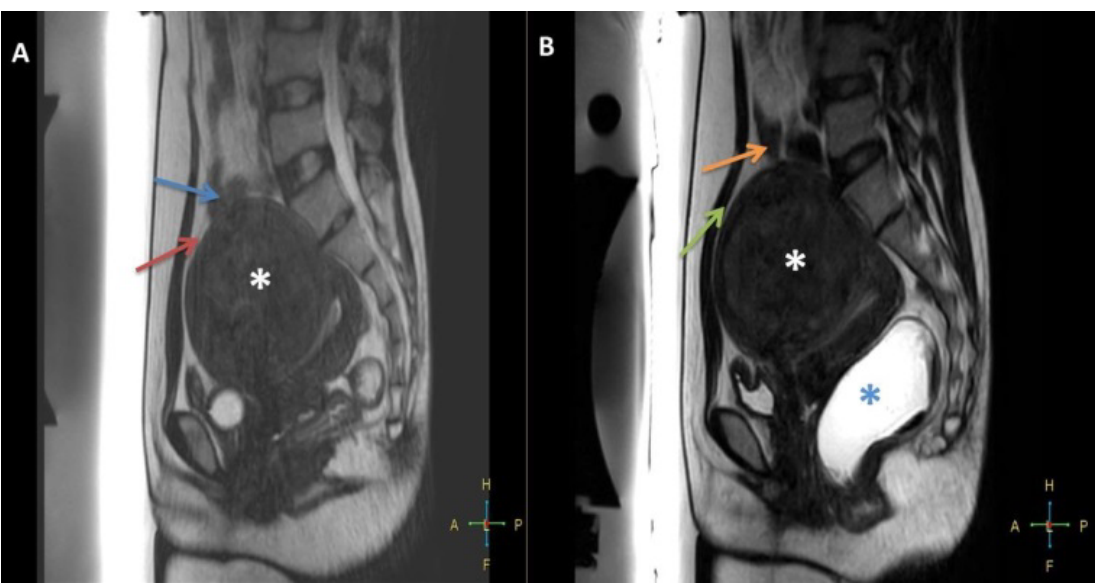

Figure 2. (A) Sagittal T2W images show the uterine fibroid on the anterior wall of the retroverted uterus (white asterisk) with bowel loops above the tumor (blue arrow) which tend to move into the space between the tumor and abdominal wall (red arrow). (B) Filling rectum with $150 \mathrm{ml}$ ultrasound gel (blue asterisk) generates upward and forward uterine movements, shrinks the space between the tumor and abdominal wall (green arrow), and bowel loops out of the treatment window (orange arrow).
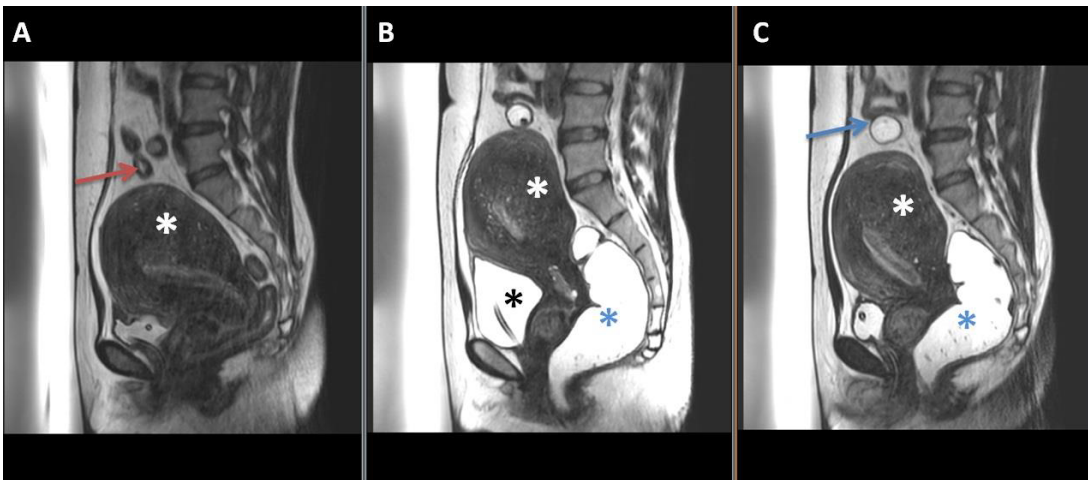

Figure 3. (A) Sagittal T2W images show the focal adenomyosis on the posterior wall of the anteverted uterus (white asterisk) with bowel loops above the tumor (red arrow). (B) Filling bladder with $300 \mathrm{ml}$ normal saline (black asterisk) and filling rectum with $150 \mathrm{ml}$ ultrasound gel (blue asterisk) generate uterus move upward and forward. (C) Emptying bladder meanwhile with the pressure of filled rectum makes the uterus move forward and downward and bowel loops out of the treatment window (blue arrow).

a rectum full of ultrasound gel is predicted to produce a non-bowel treatment window as seen in Figure $3[9,10]$. In some circumstances, after emptying bladder, the bowel loops tend to relocate into the treatment window; thus, refilling the bladder with normal saline and keeping the bladder dilated during the treatment process should be considered. Kim et al. [10] stated that the most significant factor affected to the unsuccessful rate of BRB technique was the small size of uterus.

\section{Conclusion}

The BRB maneuver technique plays an important role in generating a non-bowel treatment window for HIFU ablation of uterine fibroids and adenomyosis.

\section{Disclosure statement}

Conflict of interest: The authors of this manuscript report no conflict of interest. 


\section{REFERENCES}

1. Stewart EA. Uterine fibroids. N. Engl. J. Med. 372, 1646-1655 (2015).

2. Bergholt T, Eriksen L, Berendt $\mathrm{N}$ et al. Prevalence and risk factors of adenomyosis at hysterectomy. Hum. Reprod. 16, 2418-2421 (2001).

3. Ferrari F, Arrigoni F, Miccoli A et al. Effectiveness of magnetic resonance-guided focused ultrasound surgery. Radiol. Med. 121, 153-161 (2016).

4. Behera MA, Leong M, Johnson L et al. Eligibility and accessibility of magnetic resonanceguided focused ultrasound (MRgFUS) for the treatment of uterine leiomyomas. Fertil. Steril.
94, 1864-1868 (2010).

5. Arleo EK, Khilnani NM, Ng A et al. Features influencing patient selection for fibroid treatment with magnetic resonance-guided focused ultrasound. J. Vasc. Interv. Radiol. 18, 681-685 (2007)

6. Zhang X, Li K, Xie B et al. Effective ablation therapy of adenomyosis with ultrasoundguided high-intensity focused ultrasound. Int. J. Gynaecol. Obstet. 124, 207-211 (2014).

7. Ko JKY, Seto MTY, Cheung, VYT. Thermal bowel injury after ultrasound-guided highintensity focused ultrasound for uterine adenomyosis. Ultrasound. Obstet. Gynecol. 27, 1-6 (2017).
8. Hwang DW, Song HS, Kim HS et al. Delayed intestinal perforation and vertebral osteomyelitis after high-intensity focused ultrasound treatment for uterine leiomyoma. Obstet. Gynecol. Sci. 60, 490-493 (2017).

9. Kim YS, Bae DS, Park MJ et al. Techniques to expand patient selection for MRI-guided highintensity focused ultrasound ablation of uterine fibroids. AJR. Am. J. Roentgenol. 202, 443-451 (2014).

10. Kim YS, Lim HK, Rhim H. Magnetic resonance imaging-guided high-intensity focused ultrasound ablation of uterine fibroids: Effect of bowel interposition on procedure feasibility and a unique bowel displacement technique. PLoS. ONE. 11, 7-12 (2016). 